\title{
Imidazoline- and Benzamidine-Based Trypanosome Alternative Oxidase Inhibitors: Synthesis and Structure-Activity Relationship Studies
}

\author{
Published as part of the ACS Medicinal Chemistry Letters virtual special issue "Medicinal Chemistry in Portugal \\ and Spain: A Strong Iberian Alliance". \\ David Cisneros, Eduardo J. Cueto-Díaz, Tania Medina-Gil, Rebecca Chevillard, Teresa Bernal-Fraile, \\ Ramón López-Sastre, Mustafa M. Aldfer, Marzuq A. Ungogo, Hamza A. A. Elati, Natsumi Arai, \\ Momoka Otani, Shun Matsushiro, Chiaki Kojima, Godwin U. Ebiloma, Tomoo Shiba, \\ Harry P. de Koning, and Christophe Dardonville*
}

Cite This: ACS Med. Chem. Lett. 2022, 13, 312-318

Read Online

ACCESS I LIII Metrics \& More | 回 Article Recommendations | st Supporting Information

ABSTRACT: The trypanosome alternative oxidase (TAO), a mitochondrial enzyme involved in the respiration of the bloodstream form trypomastigotes of Trypanosoma brucei, is a validated drug target against African trypanosomes. Earlier series of TAO inhibitors having a 2,4-dihydroxy-6-methylbenzoic acid scaffold ("head") and a triphenylphosphonium or quinolin-1-ium cation as a mitochondrion-targeting group ("tail") were shown to be nanomolar inhibitors in enzymatic and cellular assays. We investigated here the effect of different mitochondrion-targeting cations and other scaffold modifications on the in vitro activity of this class of inhibitors. Low micromolar range activities were obtained, and the structure-activity relationship studies showed that modulation of the tail region with polar substituents is generally detrimental to the enzymatic and cellular activity of TAO inhibitors.

KEYWORDS: Trypanosome alternative oxidase inhibitor, Trypanosoma brucei, benzamidine, imidazoline, glycolysis

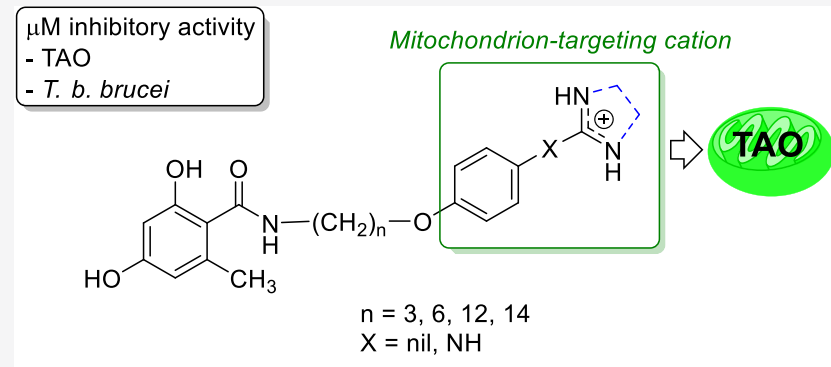

A frican trypanosomes (Trypanosoma brucei sp.) are protozoan parasites that cause sleeping sickness (human African trypanosomiasis, HAT) in sub-Saharan Africa. Bloodstream form (BSF) trypomastigotes of T. brucei possess a unique energy metabolism as they only depend on glycolysis for energy supply. ${ }^{1,2}$ In the absence of a functional oxidative phosphorylation pathway, they use the trypanosome alternative oxidase (TAO) to reoxidize the NADPH that is formed during glycolysis. $^{3}$ TAO is essential for the respiration of BSF trypomastigotes, $^{3}$ is conserved among trypanosome subspecies, ${ }^{4}$ has no counterpart in mammalian cells, and has been validated as a drug target in trypanosomes. ${ }^{5}$

The localization of TAO at the interface of the inner mitochondrial membrane ${ }^{6,7}$ has inspired the development of potent 4-hydroxybenzoate- and 4-alkoxybenzaldehyde-based inhibitors that hold a lipophilic cation as the mitochondriontargeting moiety..$^{8-10}$ In particular, 2,4-dihydroxy-6-methylbenzoate derivatives were nanomolar range TAO inhibitors showing in vitro and in vivo trypanocidal activity in a mouse model of T. $b$. rhodesiense infection (Chart 1A). ${ }^{9}$ Mitochondrial

localization of this class of inhibitors was confirmed by live-cell imaging with fluorescent analogues. ${ }^{11}$

In the current study, new analogues of the benzoate lead compound were synthesized to extend the structure-activity relationship (SAR) of this class of TAO inhibitors. The first modification was the replacement of the ester bond by a more metabolically stable amide bond. Grady et al. ${ }^{12}$ showed that this structural modification produced inhibitors that were more soluble and more stable to serum hydrolases in vivo than the benzoate counterparts. ${ }^{5}$ Second, different cationic groups were tested in place of the bulky triphenylphosphonium $\left(\mathrm{TPP}^{+}\right)$and quinolin-1-ium cations that were used in the previous series, in which positive charge is highly delocalized. ${ }^{8,9}$

Received: December 22, 2021

Accepted: January 24, 2022

Published: January 28, 2022 
Chart 1. (A) Example of Previously Reported Benzoate

TAO Inhibitors with a Triphenylphosphonium

Mitochondrion-Targeting Cation' and (B) Structural Modifications Studied in This Work

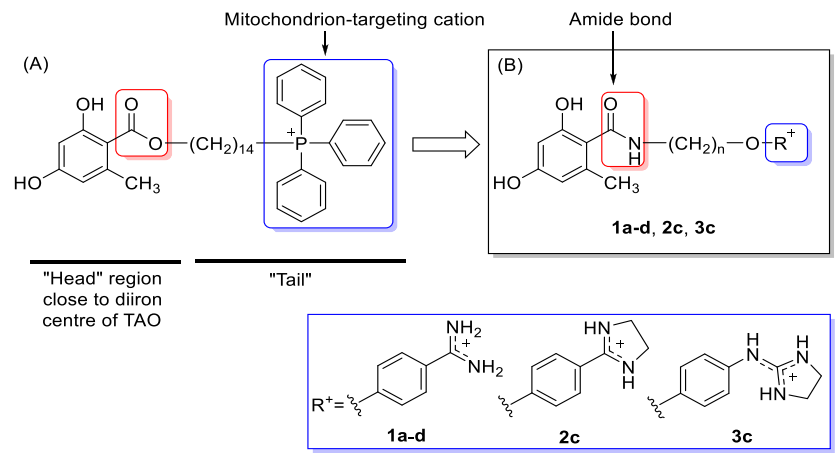

We observed previously, in model structures of $\mathrm{TPP}^{+}$-linked inhibitors binding to TAO, that the methylene linker (tail) engaged in hydrophobic interactions with the hydrophobic region of the enzyme cavity, whereas the large TPP cation extended outward into the solvent. ${ }^{9}$ In the present work, we tested the benzamidinium (1a-d), 2-phenylimidazolin-3-ium (2c), and 2-(phenylamino)imidazolin-3-ium (3c) cations as less bulky surrogates of $\mathrm{TPP}^{+}$(Chart 1). Compounds containing these cationic groups, which are found in many trypanocidal drugs (e.g., pentamidine, diminazene) and investigational compounds, are known to strongly accumulate in the mitochondrial matrix of trypanosomes, against considerable concentration gradients. ${ }^{13-19}$ We hypothesized that smaller cations would insert themselves deeper into the enzyme cavity to promote favorable interactions of the 2,4dihydroxy-6-methylbenzoic head with the enzyme active site. With the previous 4-hydroxybenzoate series, a methylene linker of less than C-14 between the TPP or quinolin-1-ium cation and the head region was detrimental to TAO inhibition. ${ }^{9,10}$ However, the imidazoline- and benzamidinebased cations used in this study are structurally different (i.e., shape, size, and electronic properties) to these cations and may present a different SAR. Hence, a methylene linker covering a wide range of lengths between the 2,4-dihydroxy-6-methylbenzoic scaffold and the cationic group were tested $\left(\left(\mathrm{CH}_{2}\right)_{n}, n\right.$ $=3,6,12,14)$. All of the compounds were assayed against recombinant TAO enzyme and wild-type (WT) and drugresistant $T . b$. brucei strains.

\section{RESULTS AND DISCUSSION}

The benzamidine derivatives with methylene linkers of $3,6,12$, and 14 units $(1 \mathbf{a}-\mathbf{d})$ were synthesized in five steps from the corresponding $\mathrm{N}$-( $n$-bromoalkyl)phthalimide $\mathbf{4 a - d}$ (Scheme 1).

Compound $4 a$ was commercially available, whereas $4 \mathbf{b}-\mathbf{d}$ were synthesized, as shown in Scheme 1. A reaction of potassium phthalimide with an excess of 1,6-dibromohexane yielded $\mathbf{4 b}$. Compounds $4 \mathrm{c}$ and $4 \mathrm{~d}$ were obtained in good yields from phthalimide and 12-bromododecan-1-ol ${ }^{20}$ or 14 bromotetradecan-1-ol ${ }^{8}$ using the Mitsunobu protocol. Reaction of $4 \mathbf{a}-\mathbf{d}$ with 4-cyanophenol and $\mathrm{K}_{2} \mathrm{CO}_{3}$ generated ethers $\mathbf{5 a}-\mathbf{d}$, which were converted to amines $\mathbf{6 a}-\mathbf{d}$ using hydrazine monohydrate. The coupling of amines $\mathbf{6 a}-\mathbf{d}$ with orsellinic acid was achieved with EDC hydrochloride and a catalytic amount of DMAP to give $7 \mathbf{a}, 7 \mathbf{c}$, and $7 \mathbf{d}$ in low to moderate
Scheme 1. Synthesis of Benzamidine Derivatives $1 \mathrm{a}-\mathrm{d}^{a}$
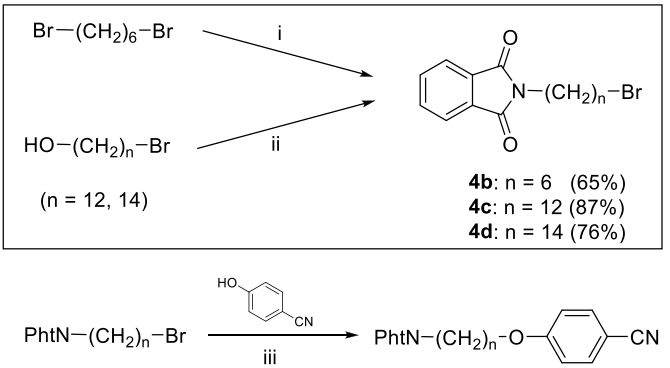

4a: $n=3$
4b: $n=6$
4c: $n=12$

5a: $n=3 \quad(81 \%)$

bb: $n=6 \quad(91 \%)$

5c: $\mathrm{n}=12(82 \%)$

5d: $n=14(76 \%)$
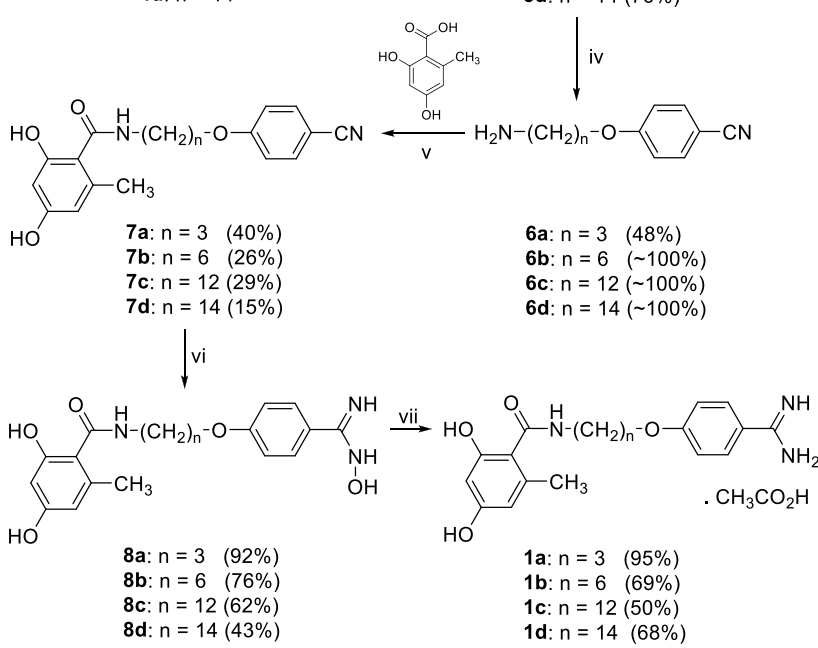

${ }^{a}$ Reagents and conditions. (i) $\mathrm{PhtN}^{-} \mathrm{K}^{+}, \mathrm{DMF}, \mathrm{rt}, 20 \mathrm{~h}$; (ii) $\mathrm{PhtNH}$, $\mathrm{Ph}_{3} \mathrm{P}$, DIAD, THF, $0{ }^{\circ} \mathrm{C}$ then rt, $20 \mathrm{~h}$; (iii) $\mathrm{K}_{2} \mathrm{CO}_{3}, \mathrm{CH}_{3} \mathrm{CN}, 80^{\circ} \mathrm{C}$, $24 \mathrm{~h}$; (iv) $\mathrm{N}_{2} \mathrm{H}_{4} \cdot \mathrm{H}_{2} \mathrm{O}$, EtOH, $80{ }^{\circ} \mathrm{C}, 12 \mathrm{~h}$; (v) for 7a, 7c, and $7 \mathrm{~d}$, EDC. $\mathrm{HCl}, \mathrm{DMAP}, \mathrm{CH}_{3} \mathrm{CN}, 80^{\circ} \mathrm{C}, 20 \mathrm{~h}$; for $7 \mathbf{b}$, PyBOP, DIPEA, $\mathrm{DMF}, \mathrm{rt}, 18 \mathrm{~h}$; (vi) $\mathrm{NH}_{2} \mathrm{OH} \cdot \mathrm{HCl},{ }^{t} \mathrm{BuOK}, \mathrm{DMSO}, \mathrm{rt}, 4$ days; (vii) (1) $\mathrm{Ac}_{2} \mathrm{O}, \mathrm{AcOH}, 15 \mathrm{~min},(2) \mathrm{H}_{2}, 5 \% \mathrm{Pd}-\mathrm{C}, \mathrm{AcOH}, \mathrm{rt}, 12 \mathrm{~h}$.

yields $(15-40 \%)$. For the synthesis of $7 \mathbf{a}$ and $7 \mathbf{b}$, another coupling agent (PyBOP) was tried, but no improvement of yield was observed (14 and $26 \%$, respectively). Of note, the yield of this amide coupling seemed to decrease with the methylene chain length of the amine, reflecting more complex reaction crudes and, possibly, solubility issues (e.g., amine $\mathbf{6 d}$ was only soluble in hot acetonitrile).

Benzamidine synthesis was achieved in a two-step process involving the formation of benzamidoximes $\mathbf{8 a}-\mathbf{d}$ followed by the catalytic hydrogenation of intermediate benzamidoximes in acetic acid/acetic anhydride to yield $\mathbf{1 a - d} .^{21}$ Imidazoline derivative $2 \mathrm{c}$ was synthesized in good yield $(76 \%)$ by reaction of the cyano derivative $7 \mathrm{c}$ with ethylenediamine $/ \mathrm{P}_{2} \mathrm{~S}_{5}$ at 120 ${ }^{\circ} \mathrm{C}$ in a sealed tube (Scheme 2). The 2-aminoimidazoline analogue $3 c$ was obtained in two steps from the amino precursor 12c using di-tert-butyl 2-thioxoimidazolidine-1,3dicarboxylate (13) following a known protocol. ${ }^{13,22}$ Compound 12c was synthesized in four steps from $4 \mathrm{c}$ and 4nitrophenol following the same route as described for the synthesis of $7 \mathbf{a}-\mathbf{d}$ (Scheme 2).

We sought to understand the role of the amide bond in the binding to the TAO active site. To do so, we tried to prepare the "keto" analogue of $\mathbf{1 d}$, with a carbonyl bond linking the methylene chain to the 5-methylresorcinol scaffold instead of an amide bond (Scheme 3a). 16-(4-Cyanophenoxy)- 
Scheme 2. Synthesis of Imidazoline (2c) and 2 Aminoimidazoline (3c) Derivatives ${ }^{a}$<smiles>Cc1cc(O)cc(O)c1C(=O)NCCCNCCN</smiles><smiles>[R]CCOc1ccc([N+](=O)[O-])cc1</smiles>

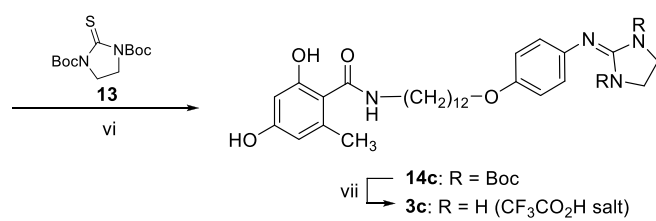

${ }^{a}$ Reagents and conditions: (i) $\mathrm{P}_{2} \mathrm{~S}_{5}, 1,2$-ethylenediamine, sealed tube, $120{ }^{\circ} \mathrm{C}, 2 \mathrm{~h}$; (ii) $\mathrm{K}_{2} \mathrm{CO}_{3}, \mathrm{CH}_{3} \mathrm{CN}, 80{ }^{\circ} \mathrm{C}$; (iii) $\mathrm{N}_{2} \mathrm{H}_{4} \cdot \mathrm{H}_{2} \mathrm{O}, \mathrm{EtOH}, 80$ ${ }^{\circ} \mathrm{C}$; (iv) EDC. $\mathrm{HCl}, \mathrm{DMAP}, \mathrm{CH}_{3} \mathrm{CN}, \mathrm{CH}_{2} \mathrm{Cl}_{2}, 80{ }^{\circ} \mathrm{C}$; (v) $\mathrm{H}_{2}, \mathrm{MeOH}$, $\mathrm{Pd}-\mathrm{C} 5 \%$; (vi) $\mathrm{HgCl}_{2}, \mathrm{Et}_{3} \mathrm{~N}, \mathrm{DMF}, 0{ }^{\circ} \mathrm{C}$ to rt; (vii) $\mathrm{CH}_{2} \mathrm{Cl}_{2}$, TFA, 0 ${ }^{\circ} \mathrm{C}$.

hexadecanoic acid $\mathbf{1 8}$ was synthesized in three steps from 16hydroxyhexadecanoic acid 15. Friedel-Crafts acylation of 5methylresorcinol with 18 using $\mathrm{AlCl}_{3}$ gave a 23:20:57 mixture of three isomers $\mathbf{1 9 / 2 0 / 2 1}$ as detected by HPLC-MS. Compounds 20 and 21 were isolated (18 and $17 \%$ yield, respectively) and characterized by ${ }^{1} \mathrm{H}$ and ${ }^{13} \mathrm{C}$ NMR. However, we were unable to isolate the desired isomer 19 from the mixture due to very similar chromatographic behavior with 20 and 21. Attempts at the synthesis with a different Lewis acid (i.e., $\mathrm{BF}_{3}-\mathrm{Et}_{2} \mathrm{O}$ ) led to the formation of more complex reaction mixtures. As an alternative route, the reaction of 2,4dihydroxy-6-methylbenzaldehyde 22 with the Grignard reagent of 23 was tried several times using different conditions but without success (Scheme 3b). Hence, attempts to obtain sufficiently pure 19 were dropped. Nevertheless, the biological activity of intermediates $\mathbf{2 0}$ and $\mathbf{2 1}$, useful for SAR studies, is reported in Table 1.

Biology. The trypanocidal activity of compounds $1 \mathrm{a}-\mathrm{d}, \mathbf{2 c}$, $3 c, 7 a-d$, and $8 a-d$ and synthetic intermediates $11 c, 12 c, 14 c$, 20, and 21 against wild-type (s427) and drug-resistant strains of T. b. brucei (i.e., B48, AQP1-3 KO) was determined in vitro using a resazurin-based assay. ${ }^{8,9}$ In general, a methylene linker of 12 carbons gave the lowest $\mathrm{EC}_{50}$ values against $T$. brucei (compare $\mathbf{1 a}-\mathbf{d} / \mathbf{7 a - d} / \mathbf{8 a}-\mathbf{d}$ ). Target compounds $1 \mathrm{c}, \mathbf{2 c}$, and $3 c$ were the most effective compounds of the series with $\mathrm{EC}_{50}$ values of $<4 \mu \mathrm{M}$ against $T$. brucei (Table 1). Among them, the 2-phenylimidazolin-3-ium derivative $2 \mathrm{c}$ was marginally more active with $\mathrm{EC}_{50}=1.72 \mu \mathrm{M}$. This finding was in agreement with previous reports on TAO inhibitors showing that a decrease in efficacy against T. $b$. brucei growth inhibition was observed as chain length decreased. ${ }^{8,9,23}$ Hence, compounds with short linkers (C-3) were poorly active (7a) or inactive $(\mathbf{1} \mathbf{a}, \mathbf{8 a})$ against $T$. brucei. Substituents in the para position of the phenoxy group affected the trypanocidal activity in the following order: 2-phenylimidazolin-3-ium (2c) $>2$ (phenylamino)imidazolin-3-ium $(3 \mathrm{c}) \approx$ benzamidinium $(1 \mathrm{c})$ $>N$-hydroxyamidine $(8 \mathrm{c}) \approx 4-\mathrm{NO}_{2}(11 \mathrm{c})$.

Apparently, the effect of changing the amide connecting group in $\mathbf{7 d}$ with a keto bond (20) was favorable for anti- $T$. brucei activity, as shown by the 2.5-fold lower $\mathrm{EC}_{50}$ of 20 (5.8 $\mu \mathrm{M})$ versus $7 \mathbf{d}(14.8 \mu \mathrm{M})$. However, because $7 \mathbf{d}$ and 20 are slightly different isomers (2,4-dihydroxy-6-methyl and 2,6dihydroxy-4-methyl, respectively), an isomer-dependent effect cannot be ruled out. Wild-type and drug-resistant strains showed virtually the same susceptibility toward these compounds (within 2-fold difference), indicating that the compounds, unlike some other benzamidines such as

\section{Scheme 3. (a) Synthesis of Derivatives 19-21 and (b) Attempted Route toward Compound $19^{a}$}

(a)

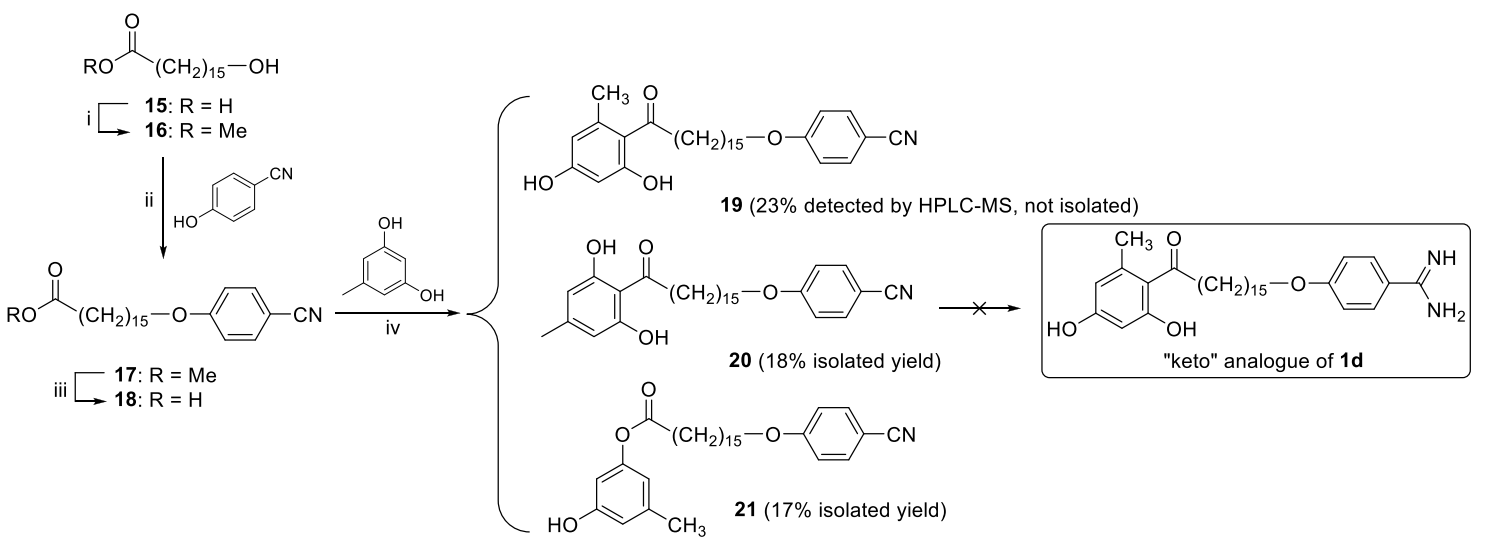

(b)

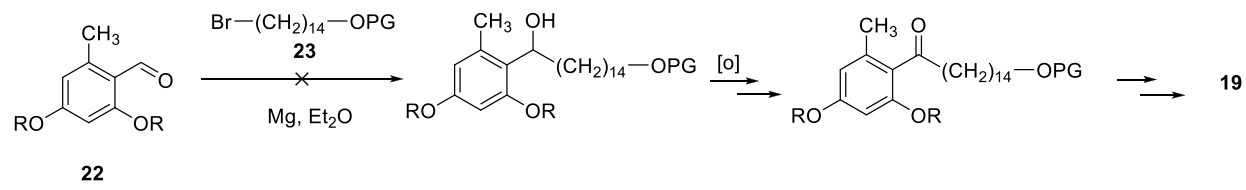

${ }^{a}$ Reagents and conditions: (i) $\mathrm{MeOH}, \mathrm{TsOH}-\mathrm{H}_{2} \mathrm{O}, \mathrm{rt}, 21 \mathrm{~h},(96 \%)$; (ii) $\mathrm{PPh}_{3}, \mathrm{DIAD}, \mathrm{THF}, 0{ }^{\circ} \mathrm{C}$ to rt, $4 \mathrm{days}(58 \%)$; (iii) $\mathrm{LiOH} \cdot \mathrm{H}_{2} \mathrm{O}, \mathrm{THF} /$ $\mathrm{MeOH} / \mathrm{H}_{2} \mathrm{O}$ (2/1/1), rt (94\%); (iv) $\mathrm{AlCl}_{3}, 1,2$-dichloroethane, $100{ }^{\circ} \mathrm{C}, 24 \mathrm{~h}$. 
Table 1. In Vitro Activity of Amidines (1a-d), Hydroxyamidines (8a-d), Imidazolines (2c, 3c, and 14c), and Synthetic Intermediates $(7 a-d, 11 c, 12 c, 20$, and 21$)$

\begin{tabular}{|c|c|c|c|c|c|c|c|c|c|c|}
\hline \multirow[b]{3}{*}{ cmpd } & \multirow[b]{3}{*}{$n$} & \multicolumn{5}{|c|}{ T. b. brucei } & \multicolumn{2}{|c|}{ cytotoxicity } & \multirow[t]{3}{*}{$\begin{array}{c}\mathrm{rTAO}^{g} \% \text { inhibition at } \\
40 \mu \mathrm{M}\end{array}$} & \multirow{3}{*}{$\frac{\mathrm{rTAO}}{\mathrm{IC}_{50}(\mu \mathrm{M})}$} \\
\hline & & \multicolumn{5}{|c|}{$\mathrm{EC}_{50}(\mu \mathrm{M})$} & \multicolumn{2}{|c|}{$\mathrm{CC}_{50}(\mu \mathrm{M})$} & & \\
\hline & & $\mathrm{WT}^{a}$ & $\mathrm{~B} 48^{b}$ & $\mathrm{RF}^{c}$ & AQP1-3 $\mathrm{KO}^{d}$ & $\overline{\mathrm{RF}^{c}}$ & HEK $^{e}$ & $\mathrm{SH}^{f}$ & & \\
\hline $1 \mathrm{a}$ & 3 & $>100$ & $>100$ & & nd & & $>200$ & & $48 \%$ & $>40^{j}$ \\
\hline $1 b$ & 6 & $15.5 \pm 0.6$ & $28.0 \pm 0.5$ & 1.8 & $17.4 \pm 0.9$ & 1.1 & $>200$ & $>12.9$ & $12.5 \%$ & $>40$ \\
\hline $1 c$ & 12 & $3.3 \pm 0.2$ & $3.6 \pm 0.1$ & 1.1 & nd & & $43.5 \pm 5.4$ & 13.2 & $39.3 \%$ & $>40$ \\
\hline $1 d$ & 14 & $18.6 \pm 1.1$ & $28.9 \pm 5.2$ & 1.6 & nd & & $>200$ & 10.7 & $31.4 \%$ & $>40$ \\
\hline $2 c$ & 12 & $1.7 \pm 0.3$ & nd & & $2.9 \pm 0.4$ & 1.7 & $67.2 \pm 0.8^{h}$ & 39.1 & $10.0 \%^{i}$ & $>10$ \\
\hline $3 c$ & 12 & $2.7 \pm 0.4$ & nd & & $3.92 \pm 0.03$ & 1.4 & $>100^{h}$ & $>36.5$ & $46.3 \%^{i}$ & $22.5 \pm 0.3$ \\
\hline $7 \mathbf{a}$ & 3 & $37.2 \pm 3.4$ & $50.8 \pm 2.7$ & 1.4 & nd & & $>200$ & $>5.3$ & $28.8 \%$ & $>40$ \\
\hline $7 \mathbf{b}$ & 6 & $30.4 \pm 0.4$ & $27.7 \pm 2.0$ & 0.9 & $30.5 \pm 0.7$ & 1.0 & $>200$ & 6.6 & $96.2 \%$ & $1.5 \pm 0.1$ \\
\hline $7 \mathrm{c}$ & 12 & $15.6 \pm 0.7$ & $15.9 \pm 0.7$ & 1.0 & nd & & $57.1 \pm 0.1$ & 3.7 & $27.4 \%$ & $>40$ \\
\hline $7 d$ & 14 & $14.8 \pm 0.5$ & $15.7 \pm 0.5$ & 1.1 & nd & & $56.8 \pm 0.2$ & 3.8 & $89.7 \%$ & $16.4 \pm 0.7$ \\
\hline $8 a$ & 3 & $>100$ & $>100$ & & nd & & $>200$ & & 14.1 & $>40$ \\
\hline $8 b$ & 6 & $19.5 \pm 1.0$ & $36.0 \pm 1.8$ & 1.9 & $21 \pm 1$ & 1.1 & $76.8 \pm 7.2$ & 3.9 & $-14.9 \%$ & $>40$ \\
\hline $8 c$ & 12 & $8.4 \pm 1.1$ & $9.1 \pm 0.5$ & 1.1 & & & $108.9 \pm 1.6$ & 13 & 44.8 & $>40$ \\
\hline $8 d$ & 14 & $29.0 \pm 2.2$ & $27.1 \pm 2.4$ & 0.9 & nd & & $>200$ & 6.9 & $-3.4 \%$ & $>40$ \\
\hline $11 \mathrm{c}$ & 12 & $9.5 \pm 0.5$ & nd & & $10.2 \pm 0.7$ & 1.1 & $>100^{h}$ & $>10.5$ & $53.8 \%^{i}$ & $30.0 \pm 1.5$ \\
\hline $12 \mathrm{c}$ & 12 & $20.3 \pm 1.3$ & nd & & $29.6 \pm 2.2$ & 1.5 & $>100^{h}$ & $>4.9$ & nd & nd \\
\hline $14 c$ & 12 & $10.4 \pm 0.7$ & nd & & $15.7 \pm 0.3$ & 1.5 & $>100^{h}$ & $>9.6$ & nd & nd \\
\hline 20 & 15 & $5.8 \pm 0.7$ & nd & & $8.2 \pm 0.9$ & 1.4 & $>100^{h}$ & $>17.1$ & $13.4 \%^{i}$ & $>10$ \\
\hline 21 & 15 & $>100$ & nd & & $>100$ & & $>100^{h}$ & & $30.0 \%^{i}$ & $>10$ \\
\hline diminazene & & $0.095 \pm 0.011$ & $0.107 \pm 0.019$ & 1.1 & & & & & & \\
\hline pentamidine & & $0.004 \pm 0.001$ & $0.208 \pm 0.021$ & 49.5 & $0.046 \pm 0.003$ & 10.8 & & & & \\
\hline $\begin{array}{l}\text { phenylarsine } \\
\text { oxide }\end{array}$ & & & & & & & $0.9 \pm 0.1$ & & & \\
\hline ascofuranone & & & & & & & & & $100 \%$ & \\
\hline
\end{tabular}

${ }^{a}$ Bloodstream form trypomastigotes of T. b. brucei strain $427(n=3) .{ }^{b}$ T. $b$. brucei strain resistant to pentamidine $(n=3) .{ }^{c}$ Resistance factor relative to WT. ${ }^{d}$ T. brucei cell line from which all aquaporins were knocked out $(n=3) .{ }^{e}$ Cytotoxicity on human embryonic kidney cells $(n=3) .{ }^{f}$ Selectivity index $(\mathrm{SI})=\mathrm{CC}_{50} / \mathrm{EC}_{50}(\mathrm{WT}) .{ }^{g}$ Purified recombinant trypanosome alternative oxidase $(\Delta \mathrm{MTS}-\mathrm{TAO})^{9}$ from $T$. b. brucei $(n=3)$; compound concentration $=40 \mu \mathrm{M} .{ }_{n}{ }_{n}=2 .{ }^{i}$ Compound tested at $10 \mu \mathrm{M}$ concentration. ${ }^{j}$ No reliable $\mathrm{IC}_{50}$ could be obtained for inhibitors with less than $40 \%$ single-point inhibition as a sigmoidal curve could not be generated.

pentamidine, $^{24}$ are not dependent on aquaporins, or on the aminopurine transporter TbAT1, for uptake by T. brucei. Cytotoxicity against HEK cells was low, resulting in selectivity indexes of $>10$ for $\mathbf{1 b}-\mathbf{d}$ to $>36.5$ for $\mathbf{2 c}$ and $3 \mathbf{c}$.

The compounds were screened at a single concentration (either 10 or $40 \mu \mathrm{M}$ ) as inhibitors of the ubiquinol oxidase activity of purified $\triangle$ MTS-TAO. The $\mathrm{IC}_{50}$ values of the compounds displaying the best percentage of inhibition were also determined (Table 1). ${ }^{9}$ In general, the benzamide derivatives reported here were poor TAO inhibitors, with $\mathrm{IC}_{50}$ values in the micromolar range compared to the nanomolar range inhibitors reported previously., ${ }^{8,9}$ The best inhibitors were the uncharged 4-cyanophenoxy analogues $7 \mathbf{b}$ $\left(\mathrm{IC}_{50}=1.52 \mu \mathrm{M}, \mathrm{C}-6\right.$ methylene linker $)>7 \mathrm{~d}\left(\mathrm{IC}_{50}=16.4 \mu \mathrm{M}\right.$, $\mathrm{C}-14$ methylene linker). More polar substituents in the para position of the phenoxy group such as 2-(phenylamino)imidazolin-3-ium (3c) or $4-\mathrm{NO}_{2}$ (11c) gave less potent inhibitors $\left(\mathrm{IC}_{50}=22.5\right.$ and $30 \mu \mathrm{M}$, respectively). These SAR results regarding TAO activity were consistent with previous work showing that the introduction of polar substituents in the tail region of TAO inhibitors is not well-tolerated, leading to a strong decrease in inhibitory potency. ${ }^{23}$ This effect seems to be counterbalanced when lipophilic cations such as $\mathrm{TPP}^{+}$or quinolin-1-ium are used, but in that case, the linker length in the tail region must be long enough $(\geq \mathrm{C}-14)$ to allow the bulky TPP cation to remain outside the enzyme active site, giving rise to low nanomolar TAO inhibitors. ${ }^{5,9}$ For the benzamidine-based TAO inhibitors $1 \mathrm{a}-\mathbf{d}$, a linkage of 14 methylene units did not improve TAO inhibition versus the $\mathrm{C}$ 12 linker, as opposed to the previous series having a quinolinium or TPP cations. ${ }^{9}$ In that case, the aromatic moieties of TPP and quinolinium cations interact with the surface of the enzyme, and the linker length must give the flexibility to the aromatic ring to orient itself optimally. Apparently, such interactions may not happen for the benzamidine compounds reported here.

Unfortunately, our efforts to isolate pure keto analogue 19, which would have informed about the effect of the amide bond on TAO inhibitory activity, were unsuccessful. However, the lack of TAO inhibition by the structurally close analogue 20 seems to indicate that the keto connection is not substantially superior to the amide linkage.

A positive correlation between $\operatorname{cog} \mathrm{P}$ and the cellular activity against $T$. brucei was observed for the cationic derivatives $1 \mathrm{a}-$ d, 2c, 3c, and 8a-d (Figure 1a) and the noncationic derivatives $7 \mathbf{a}-\mathbf{d}, \mathbf{1 1}$, 12c, 14c, and 20 (Figure 1b), although this was disconnected from inhibition of purified rTAO. A similar trend was observed by West and co-workers in a series of noncationic TAO inhibitors structurally related to ascofuranone. However, in this case, $\operatorname{clog} \mathrm{P}$ also correlated with TAO inhibition. ${ }^{23}$ The positive effect of compound lipophilicity on the efficacy against $T$. brucei of the derivatives 
(a)

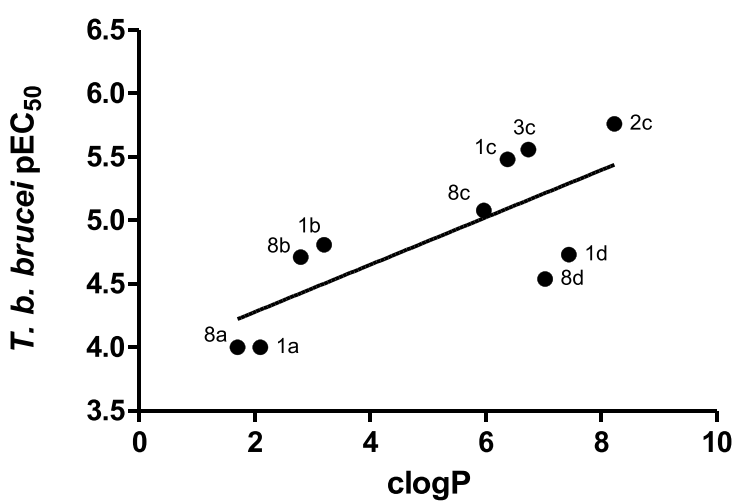

(b)

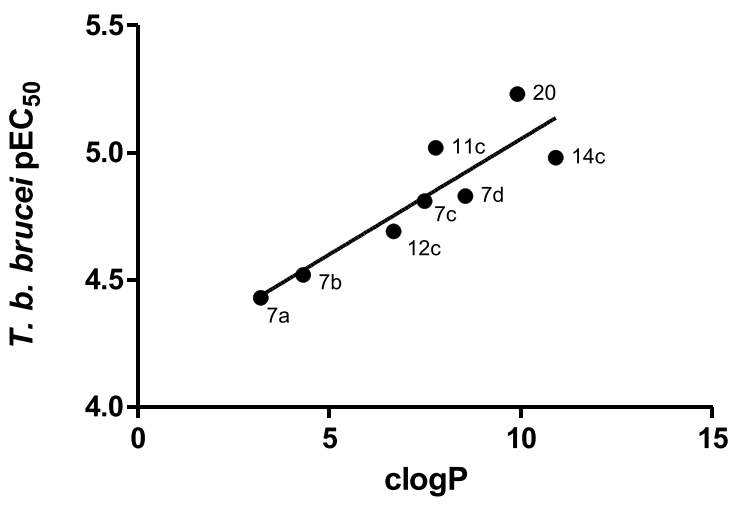

Figure 1. Correlations of $c \log \mathrm{P}$ versus $T . b$. brucei $\mathrm{pIC}_{50}$ growth inhibition for (a) cationic and (b) noncationic derivatives.

possibly reflects an increase in the permeability of the compounds through the cell and/or mitochondrial membranes, in agreement with previous studies on mitochondriontargeted antiparasitic compounds. ${ }^{8-10}$ As reported previously, the accumulation of cationic compounds (e.g., $1 \mathbf{a}-\mathbf{d}, \mathbf{2 c}, \mathbf{3} \mathbf{c}$, and $\mathbf{8 a}-\mathbf{d}$ ) in the T. brucei mitochondrion is expected to affect the mitochondrial membrane potential $\Psi_{\mathrm{m}}$ by disruption of mitochondrial functions involved in maintaining the ion gradients. ${ }^{11,25}$ Hence, the absence of correlation between rTAO inhibition and T. brucei growth is probably the result of several factors including activity against multiple targets.

To conclude, this study showed that the replacement of $\mathrm{TPP}^{+}$or quinolin-1-ium groups with imidazoline- and benzamidine-based mitochondrion-targeting cations was detrimental to the enzymatic and cellular activity of TAO inhibitors compared with previous series having the same 2,4-dihydroxy6-methylbenzoic acid head. The comparatively weak micromolar range activity against TAO of these compounds illustrates the difficulty of modulating the tail region of TAO inhibitors with polar substituents without losing efficacy. Nevertheless, the 2-(phenylamino)imidazolin-3-ium group (3c) provided an inhibitor that was active against TAO and T. brucei in the low micromolar range, with adequate selectivity versus mammalian HEK cells.

\section{EXPERIMENTAL SECTION}

T. brucei Susceptibility Assays. BSF trypanosomes of monomorphic strains Lister 427 (WT), multi-drug-resistant clone $\mathrm{B} 48$, and the $\mathrm{AQP1} 1-3 \mathrm{KO}$, which lacks all aquaglyceroporins, ${ }^{26}$ were grown in complete HMI-9 with $10 \%$ fetal bovine serum, exactly as described, and tested using a standard resazurin-based assay with 23 doubling dilutions for each compound starting at $100 \mu \mathrm{M} .{ }^{27}$ Human embryonic kidney (HEK) cells were cultured and assayed with a resazurin-based assay exactly as described previously. ${ }^{9} \mathrm{EC}_{50}$ values were calculated by nonlinear regression with an equation for a sigmoid curve with variable slope (Prism 8.0, GraphPad).

Inhibition of rTAO. The test compounds were assayed as inhibitors of the ubiquinol oxidase activity of purified $\triangle \mathrm{MTS}$-TAO by recording the absorbance change of ubiquin-1-ol at $278 \mathrm{~nm}$ exactly as previously described. ${ }^{9}$ Briefly, determination of $\triangle \mathrm{MTS}$-TAO activity was performed on a V-630 Jasco UV-vis spectrophotometer (Jasco Corporation, Tokyo, Japan) by measuring the change in absorbance of the substrate ubiquinol $\left(\varepsilon_{278}=15,000 \mathrm{M}^{-1} \mathrm{~cm}^{-1}\right)$ at $278 \mathrm{~nm}$ over a period of $2 \mathrm{~min}$ in a $1 \mathrm{~cm}$ cuvette. The recombinant enzyme was preincubated for $2 \mathrm{~min}$ in a $50 \mathrm{mM}$ Tris- $\mathrm{HCl}(\mathrm{pH} \mathrm{7.4)}$ buffer containing the detergent octaethylene glycol monododecylether $(0.05 \%(\mathrm{w} / \mathrm{v}))$ in a total reaction volume of $1 \mathrm{~mL}$ at $25{ }^{\circ} \mathrm{C}$. Reactions were initiated by the addition of ubiquinol to the cuvette. The inhibition reaction assay was performed by preincubating a fixed amount of rTAO with varying amounts of the inhibitor for $2 \mathrm{~min}$ in the same buffer before adding the substrate. Ascofuranone was used as positive control whereas DMSO was used as negative control. Control experiments were also carried out throughout the experiment to verify that there was no autoxidation of ubiquinol in the medium. Residual activities were plotted against the corresponding inhibitor concentration to generate the $\mathrm{IC}_{50}$ value using GraphPad Prism.

\section{ASSOCIATED CONTENT}

\section{(s) Supporting Information}

The Supporting Information is available free of charge at https://pubs.acs.org/doi/10.1021/acsmedchemlett.1c00717.

Synthesis and NMR spectra of all the target compounds $1 a-d, 2 c, 3 c, 20$, and 21 (PDF)

\section{AUTHOR INFORMATION}

\section{Corresponding Author}

Christophe Dardonville - Instituto de Química Médica, IQM-CSIC, E-28006 Madrid, Spain; @ orcid.org/00000001-5395-1932; Phone: +34 912587490;

Email: dardonville@iqm.csic.es

\section{Authors}

David Cisneros - Instituto de Quimica Médica, IQM-CSIC, E-28006 Madrid, Spain

Eduardo J. Cueto-Díaz - Instituto de Química Médica, IQM-CSIC, E-28006 Madrid, Spain; Present Address: Centro de Astrobiologia (CAB), Instituto Nacional de Técnica Aeroespacial (INTA), Torrejón de Ardoz, Madrid, Spain; ๑ orcid.org/0000-0002-3893-3987

Tania Medina-Gil - Instituto de Química Médica, IQM-CSIC, E-28006 Madrid, Spain

Rebecca Chevillard - Instituto de Química Médica, IQM-CSIC, E-28006 Madrid, Spain

Teresa Bernal-Fraile - Instituto de Química Médica, IQM-CSIC, E-28006 Madrid, Spain

Ramón López-Sastre - Instituto de Química Médica, IQM-CSIC, E-28006 Madrid, Spain

Mustafa M. Aldfer - Institute of Infection, Immunity and Inflammation, College of Medical, Veterinary and Life Sciences, University of Glasgow, Glasgow G12 8TA, United Kingdom

Marzuq A. Ungogo - Institute of Infection, Immunity and Inflammation, College of Medical, Veterinary and Life 
Sciences, University of Glasgow, Glasgow G12 8TA, United Kingdom

Hamza A. A. Elati - Institute of Infection, Immunity and Inflammation, College of Medical, Veterinary and Life Sciences, University of Glasgow, Glasgow G12 8TA, United Kingdom; (1) orcid.org/0000-0002-9339-6002

Natsumi Arai - Graduate School of Science and Technology, Department of Applied Biology, Kyoto Institute of Technology, Kyoto 606-8585, Japan

Momoka Otani - Graduate School of Science and Technology, Department of Applied Biology, Kyoto Institute of

Technology, Kyoto 606-8585, Japan

Shun Matsushiro - Graduate School of Science and Technology, Department of Applied Biology, Kyoto Institute of Technology, Kyoto 606-8585, Japan

Chiaki Kojima - Graduate School of Science and Technology, Department of Applied Biology, Kyoto Institute of Technology, Kyoto 606-8585, Japan

Godwin U. Ebiloma - Graduate School of Science and Technology, Department of Applied Biology, Kyoto Institute of Technology, Kyoto 606-8585, Japan; School of Health and Life Sciences, Teesside University, Middlesbrough TS1 3BX, United Kingdom

Tomoo Shiba - Graduate School of Science and Technology, Department of Applied Biology, Kyoto Institute of Technology, Kyoto 606-8585, Japan

Harry P. de Koning - Institute of Infection, Immunity and Inflammation, College of Medical, Veterinary and Life Sciences, University of Glasgow, Glasgow G12 8TA, United Kingdom; (1) orcid.org/0000-0002-9963-1827

Complete contact information is available at:

https://pubs.acs.org/10.1021/acsmedchemlett.1c00717

\section{Funding}

This work was funded by Ministerio de Ciencia, Innovación/ Agencia Estatal de Investigación (MCIN/AEI/10.13039/ 501100011033), through the project RTI2018-093940-B-I00 (co-funded by European Regional Development Fund, ERDF, "A way to build Europe"). This research was also supported by a fellowship grant from the Japan Society for the promotion of Science (JSPS Grant No. 17F17420) to G.U.E. M.M.A. and H.A.A.E. were funded by studentships from the Libyan government. M.A.U. was funded by the Petroleum Technology Development Fund of Nigeria.

\section{Notes}

The authors declare no competing financial interest.

\section{ACKNOWLEDGMENTS}

D.C. was a recipient of a JAE-intro fellowship financed by CSIC, JAE program.

\section{ABBREVIATIONS}

BSF trypanosome, bloodstream form trypanosome; DIAD, diisopropylazodicarboxylate; DMAP, 4-dimethylaminopyridine; HAT, human African trypanosomiasis; MTS, mitochondrion-targeting sequence; NADPH, nicotinamide adenine dinucleotide phosphate; PyBOP, benzotriazol-1-yloxytripyrrolidinophosphonium hexafluorophosphate; RF, resistance factor; TAO, trypanosome alternative oxidase; TPP, triphenylphosphonium; WT, wild-type

\section{REFERENCES}

(1) Grant, P. T.; Sargent, J. R. L-alpha-Glycerophosphate dehydrogenase, a component of an oxidase system in Trypanosoma rhodesiense. Biochem. J. 1961, 81, 206-14.

(2) Grant, P. T.; Sargent, J. R. Properties of L-alpha-glycerophosphate oxidase and its role in the respiration of Trypanosoma rhodesiense. Biochem. J. 1960, 76, 229-37.

(3) Clarkson, A. B., Jr.; Bienen, E. J.; Pollakis, G.; Grady, R. W. Respiration of bloodstream forms of the parasite Trypanosoma brucei brucei is dependent on a plant-like alternative oxidase. J. Biol. Chem. 1989, 264, 17770-17776.

(4) Nakamura, K.; Fujioka, S.; Fukumoto, S.; Inoue, N.; Sakamoto, K.; Hirata, H.; Kido, Y.; Yabu, Y.; Suzuki, T.; Watanabe, Y.-i.; Saimoto, H.; Akiyama, H.; Kita, K. Trypanosome alternative oxidase, a potential therapeutic target for sleeping sickness, is conserved among Trypanosoma brucei subspecies. Parasitol. Int. 2010, 59, 560564.

(5) Ebiloma, G. U.; Balogun, E. O.; Cueto-Díaz, E. J.; de Koning, H. P.; Dardonville, C. Alternative oxidase inhibitors: Mitochondriontargeting as a strategy for new drugs against pathogenic parasites and fungi. Med. Res. Rev. 2019, 39, 1553-1602.

(6) Menzies, S. K.; Tulloch, L. B.; Florence, G. J.; Smith, T. K. The trypanosome alternative oxidase: a potential drug target? Parasitology 2018, 145, 175-183.

(7) Shiba, T.; Kido, Y.; Sakamoto, K.; Inaoka, D. K.; Tsuge, C.; Tatsumi, R.; Takahashi, G.; Balogun, E. O.; Nara, T.; Aoki, T.; Honma, T.; Tanaka, A.; Inoue, M.; Matsuoka, S.; Saimoto, H.; Moore, A. L.; Harada, S.; Kita, K. Structure of the trypanosome cyanideinsensitive alternative oxidase. Proc. Nat. Acad. Sci. 2013, 110, 45804585.

(8) Meco-Navas, A.; Ebiloma, G. U.; Martín-Domínguez, A.; Martínez-Benayas, I.; Cueto-Díaz, E. J.; Alhejely, A. S.; Balogun, E. O.; Saito, M.; Matsui, M.; Arai, N.; Shiba, T.; Harada, S.; de Koning, H. P.; Dardonville, C. SAR of 4-Alkoxybenzoic Acid Inhibitors of the Trypanosome Alternative Oxidase. ACS Med. Chem. Lett. 2018, 9, 923-928.

(9) Ebiloma, G. U.; Díaz Ayuga, T.; Balogun, E. O.; Abad Gil, L.; Donachie, A.; Kaiser, M.; Herraiz, T.; Inaoka, D. K.; Shiba, T.; Harada, S.; Kita, K.; de Koning, H. P.; Dardonville, C. Inhibition of trypanosome alternative oxidase without its $\mathrm{N}$-terminal mitochondrial targeting signal ( $\triangle \mathrm{MTS}-\mathrm{TAO})$ by cationic and non-cationic 4hydroxybenzoate and 4-alkoxybenzaldehyde derivatives active against T. brucei and T. congolense. Eur. J. Med. Chem. 2018, 150, 385-402. (10) Fueyo González, F. J.; Ebiloma, G. U.; Izquierdo García, C.; Bruggeman, V.; Sánchez Villamañán, J. M.; Donachie, A.; Balogun, E. O.; Inaoka, D. K.; Shiba, T.; Harada, S.; Kita, K.; de Koning, H. P.; Dardonville, C. Conjugates of 2,4-dihydroxybenzoate and salicylhydroxamate and lipocations display potent anti-parasite effects by efficiently targeting the Trypanosoma brucei and Trypanosoma congolense mitochondrion. J. Med. Chem. 2017, 60, 1509-1522.

(11) Cueto-Díaz, E. J.; Ebiloma, G. U.; Alfayez, I. A.; Ungogo, M. A.; Lemgruber, L.; González-García, M. C.; Giron, M. D.; Salto, R.; Fueyo-González, F. J.; Shiba, T.; González-Vera, J. A.; Ruedas Rama, M. J.; Orte, A.; de Koning, H. P.; Dardonville, C. Synthesis, biological, and photophysical studies of molecular rotor-based fluorescent inhibitors of the Trypanosome Alternative Oxidase. Eur. J. Med. Chem. 2021, 220, 113470.

(12) Grady, R. W.; Bienen, E. J.; Dieck, H. A.; Saric, M.; Clarkson, A. B. Jr. N-n-alkyl-3,4-dihydroxybenzamides as inhibitors of the trypanosome alternative oxidase: activity in vitro and in vivo. Antimicrob. Agents Chemother. 1993, 37, 1082-1085.

(13) Dardonville, C.; Nué Martínez, J. J. Bis(2-aminoimidazolines) and Bisguanidines: Synthetic Approaches, Antiparasitic Activity and DNA Binding Properties. Curr. Med. Chem. 2017, 24, 3606-3632.

(14) Ríos Martínez, C. H.; Nué Martínez, J. J.; Ebiloma, G. U.; de Koning, H. P.; Alkorta, I.; Dardonville, C. Lowering the pKa of a bisimidazoline lead with halogen atoms results in improved activity and selectivity against Trypanosoma brucei in vitro. Eur. J. Med. Chem. 2015, 101, 806-17. 
(15) Rodríguez, F.; Rozas, I.; Kaiser, M.; Brun, R.; Nguyen, B.; Wilson, W. D.; García, R. N.; Dardonville, C. New bis(2-aminoimidazoline) and bisguanidine DNA minor groove binders with potent in vivo antitrypanosomal and antiplasmodial activity. J. Med. Chem. 2008, 51, 909-923.

(16) Wang, X.; Dong, Y.; Cal, M.; Kaiser, M.; Wittlin, S.; Vennerstrom, J. L. Antiprotozoal Selectivity of Diimidazoline NPhenylbenzamides. ACS Infect. Dis. 2015, 1, 135-139.

(17) Lanteri, C. A.; Tidwell, R. R.; Meshnick, S. R. The mitochondrion is a site of trypanocidal action of the aromatic diamidine DB75 in bloodstream forms of Trypanosoma brucei. Antimicrob. Agents Chemother. 2008, 52, 875-882.

(18) Ibrahim, H. M. S.; Al-Salabi, M. I.; El Sabbagh, N.; Quashie, N. B.; Alkhaldi, A. A. M.; Escale, R.; Smith, T. K.; Vial, H. J.; de Koning, H. P. Symmetrical choline-derived dications display strong antikinetoplastid activity. J. Antimicrob. Chemother. 2011, 66, 111-125.

(19) Millan, C. R.; Acosta-Reyes, F. J.; Lagartera, L.; Ebiloma, G.; Lemgruber, L.; Nué Martinez, J. J.; Saperas, N.; Dardonville, C.; de Koning, H.; Campos, J. L. Functional and structural analysis of ATspecific minor groove binders that disrupt DNA-protein interactions and cause disintegration of the Trypanosoma brucei kinetoplast. Nucleic Acids Res. 2017, 45, 8378-8391.

(20) Chong, J. M.; Heuft, M. A.; Rabbat, P. Solvent Effects on the Monobromination of $\alpha, \omega$-Diols: A Convenient Preparation of $\omega$ Bromoalkanols. J. Org. Chem. 2000, 65, 5837-5838.

(21) Judkins, B. D.; Allen, D. G.; Cook, T. A.; Evans, B.; Sardharwala, T. E. A Versatile Synthesis of Amidines from Nitriles Via Amidoximes. Synth. Commun. 1996, 26, 4351-4367.

(22) Dardonville, C.; Goya, P.; Rozas, I.; Alsasua, A.; Martin, M. I.; Borrego, M. J. New aromatic iminoimidazolidine derivatives as alpha1-adrenoceptor antagonists: a novel synthetic approach and pharmacological activity. Bioorg. Med. Chem. 2000, 8, 1567-1577.

(23) West, R. A.; Cunningham, T.; Pennicott, L. E.; Rao, S. P. S.; Ward, S. E. Toward More Drug Like Inhibitors of Trypanosome Alternative Oxidase. ACS Infect. Dis. 2018, 4, 592-604.

(24) Alghamdi, A. H.; Munday, J. C.; Campagnaro, G. D.; Gurvic, D.; Svensson, F.; Okpara, C. E.; Kumar, A.; Quintana, J.; Martin Abril, M. E.; Milic, P.; Watson, L.; Paape, D.; Settimo, L.; Dimitriou, A.; Wielinska, J.; Smart, G.; Anderson, L. F.; Woodley, C. M.; Kelly, S. P. Y.; Ibrahim, H. M.; Hulpia, F.; Al-Salabi, M. I.; Eze, A. A.; Sprenger, T.; Teka, I. A.; Gudin, S.; Weyand, S.; Field, M.; Dardonville, C.; Tidwell, R. R.; Carrington, M.; O’Neill, P.; Boykin, D. W.; Zachariae, U.; De Koning, H. P. Positively selected modifications in the pore of TbAQP2 allow pentamidine to enter Trypanosoma bruce. elife 2020, 9, No. e56416.

(25) Alkhaldi, A. A. M.; Martinek, J.; Panicucci, B.; Dardonville, C.; Zíková, A.; de Koning, H. P. Trypanocidal action of bisphosphonium salts through a mitochondrial target in bloodstream form Trypanosoma brucei. Int. J. Parasitol. Drugs Drug Resist. 2016, 6, 2334.

(26) Jeacock, L.; Baker, N.; Wiedemar, N.; Mäser, P.; Horn, D. Aquaglyceroporin-null trypanosomes display glycerol transport defects and respiratory-inhibitor sensitivity. PLOS Pathogens 2017, 13, No. e1006307.

(27) Rodenko, B.; Van Der Burg, A. M.; Wanner, M. J.; Kaiser, M.; Brun, R.; Gould, M.; De Koning, H. P.; Koomen, G. J. 2,N6disubstituted adenosine analogs with antitrypanosomal and antimalarial activities. Antimicrob. Agents Chemother. 2007, 51, 3796-3802.

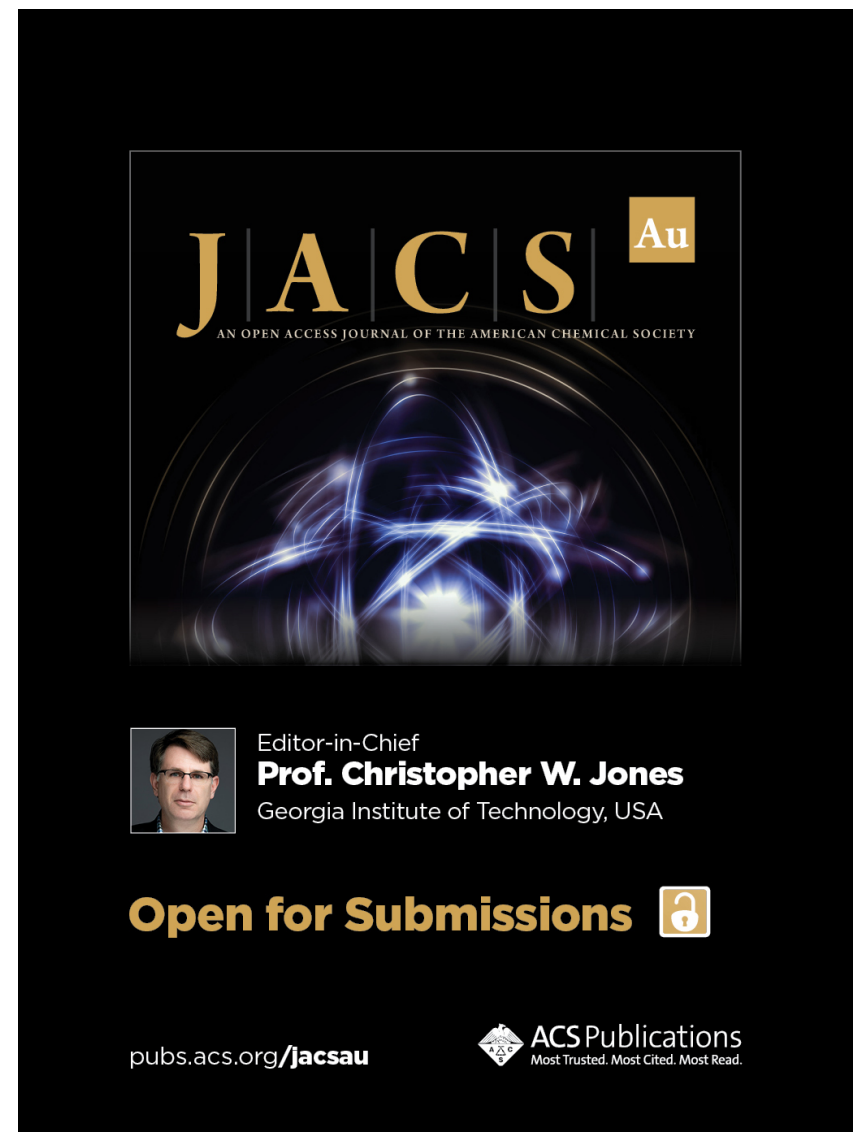

